\title{
Research of safety indicators of diesel train movement with two-stage spring suspension
}

\author{
Andriy Kuzyshyn ${ }^{1, *}$, Andriy Batig ${ }^{2}$, Sergei Kostritsa ${ }^{1}$, Julia Sobolevska ${ }^{3}$, Vitalii Kovalchuk ${ }^{3}$, Stepan Dovhanyuk ${ }^{1}$, and \\ Oleg Voznyak ${ }^{3}$ \\ ${ }^{1}$ Dnipropetrovsk National University of Railway Transport named after Academician V. Lazaryan, 49000 Dnieper, Ukraine \\ ${ }^{2}$ Lviv Research Institute of Forensic Expertise, 79000 Lviv, Ukraine \\ ${ }^{3}$ Lviv branch of Dnipropetrovsk National University of Railway Transport named after Academician V. Lazaryan, 79052 Lviv, Ukraine
}

\begin{abstract}
The problem of the interaction of rolling stock with the rail track has been analyzed in the present paper. It has been established that in the process of transport science development a number of methods for determining the causes of wheel pairs derailment are developed, which, in a varying degree, take into account the peculiarities of their interaction. The problem of choosing the most accurate method for estimating the causes of rolling stock derailment becomes more complicated because of the lack of sufficient experimental data that would allow us to verify the adequacy of the models. The indicators of stability of the wheel against derailment, which are used on the railways of Ukraine and Europe, have been examined. Their dependences on the speed of movement were derived. It has been established that the increase of the speed of motion leads to the increase of the interaction power of the rolling stock with the rail track, which may, under certain operational parameters, provoke its derailment. As a result of the calculations, it has been shown that the use of norms for car design and calculation used on Ukrainian railways can lead to an inadequate estimation of traffic safety parameters, since it does not take into account the unevenness of the railway track. It has been established that the requirements of BS EN 14363: 2005 European norms are stricter in comparison with the norms for calculation and evaluation of the bearing elements strength and dynamic qualities of motor-vehicle rolling stock used on Ukrainian railways. A comparison of the experimentally and theoretically calculated values of the stability margin coefficient against wheel derailment of the first wheel pair of the diesel train car was carried out.
\end{abstract}

\section{Introduction}

The most important problem on rail transport is to ensure the safety of train movement during operation. At the same time, the primary task is to prevent accidents and derailments. Rolling stock derailment is due to the loss of the interaction of at least one wheel of the rolling stock of the railway transport with a rail as a result of the displacement of the wheel from its normal position relatively to the rail head [1].

During movement of the wheel along the rail, vertical and horizontal forces occur, which cause the wheel flange to press on the head of the rail. Taking into account the geometry of the wheel and rail contact, such a process can lead to the displacement of the contact point on the wheel flange, and in the worst case, can lead to the wheel to roll onto the head of the rail (Fig. 1).

As a rule, the action of a considerable vertical force on the wheel is enough to make such a process impossible. However, under certain operating conditions, there can be substantial increase in horizontal force or vertical force reduction, which may cause wheel derailment.

The level of safe operation of the rolling stock on the railways is determined, mainly, by the availability of stability margin of the train. Therefore, the issue of derailment is given great importance both in theoretical and experimental studies.

The object of our research is the DPKr-2 modern passenger diesel train [2] of Kryukiv, Ukraine, carriage plant production (Fig. 1).

It should be noted that at this stage only diesel train operational tests were carried out. Theoretical studies of the power interaction of this diesel train with the rail track, as well as theoretical determination of the level of safe operation with the help of the coefficient of stability margin of the wheel against derailment have not been carried out.

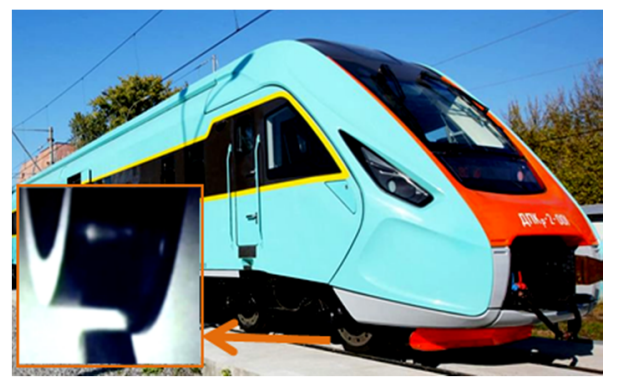

Fig. 1. The wheel rolling onto the head of the rail.

\footnotetext{
* Corresponding author: kuzyshyn1993@gmail.com
} 


\section{Analysis of literary data and problem statement}

Over a hundred years ago Nadal in his paper [3] proposed a method for determining the ratio of forces acting on the wheel, under which wheel derailment does not occur. But in this method a separate wheel is considered, and the criterion itself is based on the quasi-static conditions of the vehicle movement. Under real conditions of operation, the process of wheel pair derailment is dynamic and is the subject of further research $[4,5]$.

For dynamic simulation of wheel pair derailment, it is suggested to use modern software packages [6]. This makes it possible to simulate the movement of the whole train rather than a separate wheel pair.

In paper [7] a technique using acceleration sensors to detect early signs of wheel pair derailment is presented. The algorithm for detecting wheel pair derailment is tested by means of simulation and experimental research on a scale model of a train.

In paper [8], two safety criteria against wheel derailment are compared. The first one is based on Nadal's formulas, and the second criterion is a power one. It was noted that the power criterion is more convenient for railway transport state monitoring, since it does not require the measurement of contact forces.

In paper [9], the kinematic and geometric safety criteria against wheel derailment were researched and compared.

Applying the concept of dynamic system stability in paper [10], the mechanism of rolling stock derailment on a railway bridge was investigated. The theory of random power analysis is proposed.

In papers $[11,12]$, the studies were carried out on the modification of derailment criteria, which took into account the angle of wheel rolling on the head of the rail. It was established that taking into account the angle of wheel rolling onto the rail, when determining the possibility of wheel pair derailment, the accuracy of calculations increases.

In papers [13, 14] the method for assessing the stability of motion against wheel derailment according to the specified formula was proposed. It determines the critical magnitude of the ratio of horizontal frame strength and vertical force under given vertical load distribution. The refined formula has found wide application in experimental works on determining the maximum permissible speeds of movement of new and modernized units of rolling stock.

In current regulations of railways in Ukraine [15, 16] that are used to estimate the probability of wheel derailment, the coefficient of stability margin against wheel rolling onto the head of the rail is suggested for usage. It is believed that in the case when the value of this coefficient is less than one, the wheel pair can derail.

In paper [17], to determine the safety conditions against wheel pair derailment, the author suggests not to consider a single wheel derailment, but a wheel pair as a whole regarding it as a solid body. In this case, it is necessary to consider the possible movement of the wheel pair when wheel flange is sliding in the vertical transverse plane and runs on the head of the rail. The disadvantages of the proposed method are the failure to take into account the impact of the other wheel pairs of rolling stock, which leads to inaccuracies in the calculations.

Paper [18] formulates the power interpretation of the wheel rolling onto the head of the rail. According to the authors, this is possible when the kinetic energy of motion, which falls on a wheel pair, exceeds the work of forces that arise in the contact between the surfaces of the flange and the wheel.

Article [19] presents a brief overview of selected problems of railway vehicle dynamics that are related to traffic safety. The study of the corresponding dynamic phenomena, including the mechanism of the wheel pair derailment, is also discussed.

Works $[20,21]$ outline the approaches that are used in conducting forensic rail-transport expertise.

The analysis of publications and normative documents has shown that most of the considered methods estimate the probability of derailment for one wheel pair, without taking into account the impact of other wheel pairs, which may lead to incorrect identification of the reason for wheel pair derailment. In addition, horizontal and vertical unevenness of the track is not taken into account, although, as experience shows, the main causes of accidents and derailments on the railways of Ukraine are, first of all, the deviation in the condition of the railway track and running gears of the rolling stock from the standards.

Therefore, to approximate the results of mathematical modeling to the real conditions of operation, it is proposed to calculate wheel pair derailment because of the wheel rolling onto the head of the rail, using the dynamic equations of spatial oscillations of the car arising from the geometrical unevenness of the track in the horizontal and vertical directions.

At present the theoretical studies of power interaction of the diesel train DPKr-2 with a rail track have not been conducted. Therefore, the problem of determining the conditions for its safe operation with the help of the coefficient of stability margin against wheel derailment and the theoretical prediction of the conditions for accidents and derailments prevention is urgent.

\section{Purpose and objectives of the study}

The purpose of the work is to determine the traffic safety index, namely the stability of the wheel against rolling on the head of the rail for DPKr-2diesel train.

To achieve this goal, the following tasks were performed:

- wheel stability indicators against derailment used on the railways of Ukraine and Europe were calculated;

- operation conditions of DPKr-2 diesel train moving on a straight section of the track, which are acceptable according to Ukrainian and European norms, were studied;

- adequacy of the mathematical model was studied by comparing the obtained results during theoretical calculations with the experimental ones. 


\section{Theoretical determination of traffic safety indicators}

To obtain a spatial mathematical model that will be used to determine the dynamic characteristics of the criteria for the probability of wheel pair derailment, an analysis of the design of the diesel train car was made and its spatial mechanical model was adopted [22].

The chosen mechanical model consists of 7 solid bodies (body, two bogies, four wheel pairs), connected by elastic-dissipative joints. The body and bogies have 6 degrees of freedom, and wheel pairs have 5 , because there is no galloping for them. The possibility of taking into account the unevenness of the track in the horizontal and vertical directions is foreseen.

To describe the oscillations of the diesel train car, the mathematical model consisting of 38 second-order differential equations is obtained [23].

At present, there are a number of standard methods for determining the possibility of wheel pair derailment, which, in varying degrees, take into account the features of a wheel pair and rail track interaction. Thus, the railways of Ukraine are governed by the norms for calculating and designing motor-vehicle rolling stock [15] or carriages [16], while European railways are governed by BS EN 14363: 2005 norms.

On the basis of the performed dynamic calculations of the car of the DPKr-2 diesel train, we determine its coefficient of stability margin in motion on the straight section of the track according to different methods.

In accordance with norms [15], the coefficient of stability margin of the wheel against derailment is used as a traffic safety indicator. This criterion is the ratio of the permissible theoretical value of the driving force to the vertical load up to its experimental value. The minimum permissible value of the stability margin coefficient against wheel derailment is 1,4 .

The expression for determining the coefficient of stability margin has the form [15]:

$$
\begin{gathered}
K_{\mathrm{st}}=\left[\left(\frac{Y_{\mathrm{d}}}{N_{\mathrm{n}}}\right)_{\mathrm{T}} /\left(\frac{Y_{\mathrm{d}}}{N_{\mathrm{n}}}\right)_{\mathrm{E}}\right]= \\
\left\langle\frac{Q\left[2\left(b-a_{2}\right)-K_{\mathrm{D} 1}\left(l_{1}+a_{1}\right)+a_{2} K_{\mathrm{D} 2}\right]+Y_{f} r+q\left(b-a_{2}\right)}{Y_{f} l_{1}}+\right. \\
\mu^{\prime}\left\{Q\left[2\left(b-a_{1}\right)-K_{\mathrm{D} 2}\left(l_{1}+a_{2}\right)+a_{1} K_{\mathrm{D} 1}\right]-Y_{f} r+\right. \\
\left.q\left(b-a_{1}\right)\right\} \frac{1+\mu \sin (2 \beta)}{\beta}+\left\{Q \left[2\left(b-a_{2}\right)-K_{\mathrm{D} 1}\left(l_{1}+a_{1}\right)+\right.\right. \\
\left.\left.\left.a_{2} K_{\mathrm{D} 2}\right]+Y_{f} r+q\left(b-a_{2}\right)\right\} \mu \cos ^{2} \beta\right\rangle \frac{1}{\cot \beta+\mu}
\end{gathered}
$$

where $Y_{d}$ - the driving force; $N_{n}$ - vertical force from the wheel, which is rolling onto the head of the rail; $\mu$ - the coefficient of friction between the flange of the rolling wheel and the rail; $\beta$ - angle of inclination of the wheel flange generatrix to the horizontal plane; $Y_{f}$ - frame force acting on a wheel pair (modulo); $Q$ - weight of the suspension part of the car, which falls on the neck of the axle of the wheel pair; $K_{D 1}, K_{D 2}$ - coefficients of vertical dynamics in the 1 st degree of suspension; $\mu^{\prime}-$ the coefficient of friction between the rolling surface of the non-rolling wheel and the rail; $q$ - the weight of nonsuspended parts that falls on the wheel pair; $b$ - half distance between the points of application of vertical loads and the necks of the axle of the wheel pair; $a_{1}$ - the distance between the point of application of the vertical load on the axle neck of the rolling wheel and the contact point on the flange; $a_{2}$ - the distance between the point of vertical load application on the axle neck of the nonrolling wheel and the point of contact on the surface of its rolling; $r$ - the radius of the wheel in the circle of rolling.

Analyzing formula (1), we see that the change in the stability margin coefficient is due to the change in the frame strength and coefficients of vertical dynamics. The other parameters are constant values that do not result in the change of the stability margin coefficient against wheel's derailment during diesel train movement.

To determine the frame strength and coefficients of vertical dynamics, we use the adopted spatial mathematical model.

Since the frame force is a horizontal force acting on the axle of the wheel pair of the bogie on the body side in the transverse direction to the axis of the track, then it can be calculated by the formula:

$$
Y_{f}=2 S_{t s}\left[\left(y_{b j} \pm a_{1} \psi_{b j}+a_{7} \theta_{b j}\right)-\left(y_{w p i}\right)\right],
$$

where $S_{t s}$ - the transverse stiffness of the spring of an axlebox suspension; $y_{b j}, y_{w p i}-$ horizontal transverse displacements of the $j^{\text {th }}$ bogie of the diesel train car and its $i^{\text {-th }}$ wheel pair, respectively, $\psi_{b j}, \theta_{b j}$ - angles of wobbling and lateral oscillation of the bogie, obtained during the numerical integration of the equations of motion; $a_{1}, a_{7}$ - corresponding lengths.

In formula (2), the upper "+" sign is used for the first wheel pair of the bogie, the "-_" sign is used for the second wheel pair of the bogie.

The coefficients of vertical dynamics are determined by deflections $\Delta$ or forces $F$ in separate sets of spring suspension:

$$
K_{\mathrm{D}}=\frac{\Delta_{\mathrm{D}}}{\Delta_{\mathrm{st}}}=\frac{\left(z_{b j} \pm a_{1} \varphi_{y b j} \bar{\mp} a_{4} \theta_{b j}\right)-\left(z_{w p i} \bar{\mp} a_{4} \theta_{w p i}\right)}{\Delta_{\mathrm{st}}},
$$

where $z_{b j}, \varphi_{y b j}, \theta_{b j}, z_{w p i}, \theta_{w p i}-$ generalized coordinates of car movement of a diesel train, obtained during calculations of the spatial mathematical model; $a_{1}, a_{4}-$ corresponding lengths.

After calculating the given formulas at different speeds of the diesel train movement, we obtain the dependence of the coefficient of stability margin against wheel derailment on the speed of the first and second wheel pairs (Fig. 2).

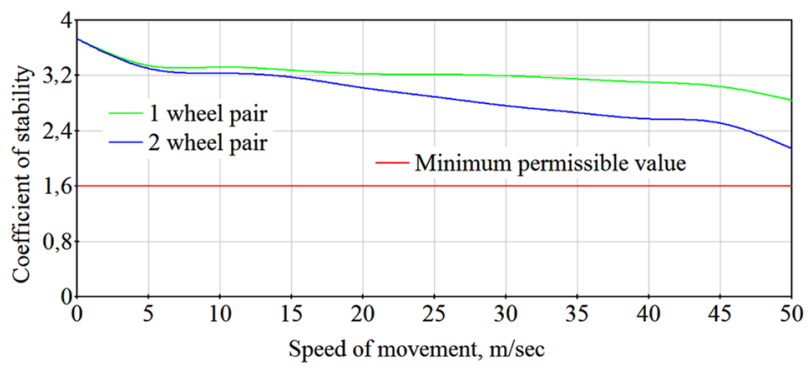

Fig. 2. Coefficient of stability margin with the length and amplitude of unevenness of $15 \mathrm{~m}$ and $0,006 \mathrm{~m}$ respectively. 
The analysis of the obtained dependencies shows that when the speed of movement increases from $0 \mathrm{~m} / \mathrm{s}$ to $50 \mathrm{~m} / \mathrm{s}$, the stability coefficient decreases in the range: I wheel pair - from 3,73 to 2,84; II wheel pair - from 3,73 to 2,14 .

The reduction of the stability margin coefficient against wheel derailment shows the increased power effect of the rolling stock on the railway track. Under certain operating conditions, it can lead to the loss of stability of the rolling stock and its derailment.

The second technique is based on the use of norms [16] for cars. According to them, the coefficient of stability of the wheel pair against derailment (under the condition of rolling onto) is determined by the formula:

$$
\begin{gathered}
K_{\mathrm{st}}=\frac{\tan \beta-\mu}{1+\mu \cdot \tan \beta} \times \\
\frac{2 Q_{n}\left[\frac{b-a_{2}}{l}\left(1-C_{v d 1}\right)-\frac{b}{l} C_{d l w}\right]+H_{f} \cdot \frac{r}{l}+q_{w p} \frac{b-a_{2}}{l}}{H_{f}+\mu\left\{2 Q_{n}\left[\frac{b-a_{1}}{l}\left(1-C_{v d}\right)+\frac{b}{l} C_{d l w}\right]-H_{f} \frac{r}{l}+q_{w p} \frac{b-a_{1}}{l}\right\}} \geq\left[K_{\mathrm{st}}\right],
\end{gathered}
$$

where $\beta$ - the angle of inclination of the wheel flange generatrix to the horizontal plane; $\mu$ - the coefficient of friction of surfaces of wheels and rails; $Q_{n}-$ the force of the weight of the suspended parts of a car, acting on the neck of the axle of the wheel pair; $q_{w p}$ - the weight of nonsuspended parts that falls on the wheel pair; $C_{v d l}-$ the estimated value of the coefficient of vertical dynamics of a car; $C_{d l w}$ - the estimated value of the coefficient of lateral wobbling dynamics; $H_{f-}-$ the calculated mean value of the frame force; $b$ - half distance between the middle parts of the axle necks; $l-$ an average distance between contact points of wheels with rails; $a_{1,2}-$ the calculated distance from the contact points to the middle of the necks of the wheel pair axle; $r$ - the radius of the wheel.

According to the results of the calculations with formula (4), the dependence of the stability coefficient of the wheel pair against derailment (under condition of rolling onto) on the speed of the diesel train car (Fig. 3) was obtained.

The analysis of the calculated data shows that when the speed of movement increases from 10 to $50 \mathrm{~m} / \mathrm{s}$, the stability coefficient of the wheel pair decreases from 7,27 to 2,01 , but remains permissible.

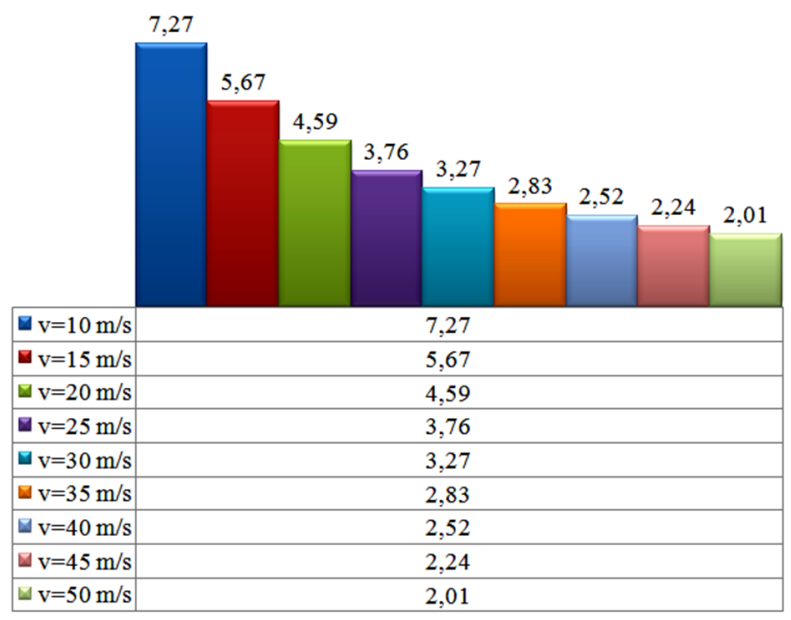

Fig. 3. Dependence of the stability coefficient of the wheel pair on the speed of movement.
It should be noted that formula (4) does not allow us to take into account the real conditions of operation, namely, vertical and horizontal unevenness of the rail track, as well as the peculiarities of the interaction of separate elements of the diesel train car design. The frame strength and coefficients of dynamics are considered constant values. All this makes it impossible to use the data obtained during the calculations of the mathematical model.

Let us turn to the analysis of European norms BS EN 14363:2005, according to which the rolling stock is considered secure against derailment if the condition (5) is performed at each stage of the test:

$$
\left(\frac{Y}{Q}\right)_{\max } \leq\left(\frac{Y}{Q}\right)_{\lim }
$$

where $Y$ - horizontal guiding force; $Q$ - vertical force from the wheel on the rail.

Using the model of the diesel train car DPKr-2, the guiding force was found to be the resultant force of the creep force and the frame strength and is determined by the formula:

$$
N_{\mathrm{n}}=\frac{Y_{f}-Y_{f r 1}-Y_{f r 2}}{\sin \gamma_{1}},
$$

where $Y_{f}$ - frame strength; $Y_{f r 1,2}$ - the forces of the creep on the first and second wheels of the wheel pair respectively; $\gamma_{1}$ - the conicality of the wheel flange of the wheel pair.

It should be noted that the guiding force occurs only when the gap between the wheel flange and the rail head is exhausted. In the presence of a gap, the guide force is zero. Since the mutual horizontal movement of the wheel and the rails is calculated at each step of the integration, the proposed model allows for tracking the instant when the clearance between the flange and the rail head becomes zero and for calculating the guide force.

It should be noted that the use of European norms BS EN 14363: 2005 to determine the possibility of a wheel derailment is practically impossible without the use of computer simulations, since it is necessary to calculate a guiding force, which requires tracking the instant when the gap between the flange and the rail head becomes equal to zero.

By calculation, we check the fulfillment of condition (5) at different speeds of the diesel train movement (Fig. 4). The calculation is performed with a horizontal unevenness for $15 \mathrm{~m}$ and its amplitude for $0,006 \mathrm{~m}$, which corresponds to the good condition of the railway track.

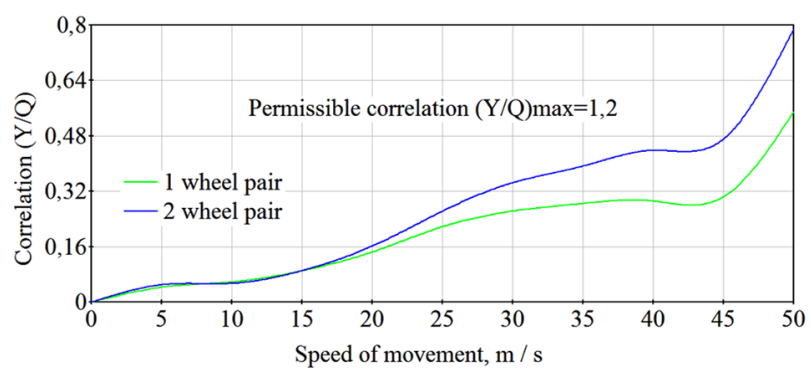

Fig. 4. Dependence of the ratio $(Y / Q)$ on the speed of the first and second wheel pairs. 
From the obtained dependences, it follows that an increase in the speed from $0 \mathrm{~m} / \mathrm{s}$ to $50 \mathrm{~m} / \mathrm{s}$ leads to the increase in the numerical value of the ratio $(Y / Q)$ : for the first wheel pair - from 0 to 0,55 ; for the second one - from 0 to 0,79 , which is close to the permissible value and can, under certain operating conditions, cause accidents and derailments.

Using the proposed approach for determining the safety indicators, the maximum permissible speed of the DPKr-2 diesel train car was determined at a given horizontal unevenness of the track (Table 1).

The sign "-" means the realization of the condition of derailment and the danger for the diesel train car movement.

The norms [15] used in Ukraine allow for movement of a diesel train car at a speed of $115-120 \mathrm{~km} / \mathrm{h}$, but BS EN 14363: 2005 European norms do not allow it.

Table 1. Permissible speed of the diesel train car movement.

\begin{tabular}{|c|c|c|c|}
\hline \multirow{2}{*}{$\begin{array}{c}\text { Speed, } \\
\mathrm{km} / \mathrm{h}\end{array}$} & \multicolumn{4}{|c|}{$\begin{array}{c}\text { Traffic safety indices with an unevenness of } 20 \mathrm{~m} \text { and } \\
\text { an amplitude of } 10 \mathrm{~mm}\end{array}$} \\
\cline { 2 - 4 } & $\begin{array}{c}\text { European norms on } \\
\text { the condition of } \\
\text { derailment }\end{array}$ & $\begin{array}{c}\text { Norms [15] on the } \\
\text { condition of } \\
\text { derailment }\end{array}$ & $\begin{array}{c}\text { Car } \\
\text { norms } \\
{[16]}\end{array}$ \\
\hline 150 & - & - & + \\
\hline 145 & - & - & + \\
\hline 140 & - & - & + \\
\hline 135 & - & - & + \\
\hline 130 & - & - & + \\
\hline 125 & - & - & + \\
\hline 120 & - & + & + \\
\hline 115 & - & + & + \\
\hline 110 & + & + & + \\
\hline 105 & + & + & + \\
\hline
\end{tabular}

It was found out that the norms for cars [16], which do not take into account rail track unevenness, permit the diesel train to drive at the maximum permissible speed. However, according to the norms [15], with a given horizontal unevenness, the speed of up to $120 \mathrm{~km} / \mathrm{h}$ is permissible. Thus, consideration of the track state significantly affects the traffic safety indicators. Using the coefficient of stability margin against the wheel derailment, which is calculated according to the norms [16], may lead to an unreliable estimation of traffic safety parameters, because the failure to take into account actual operating conditions can cause serious accidents.

In general, it can be stated that the requirements of the European norms for the DPKr-2 diesel train are more stringent than the requirements of norms used in Ukraine.

The obtained results can be used to establish safe speeds of diesel train movement on straight sections of the track in the presence of vertical and horizontal unevenness.

\section{Experimental determination of the stability margin coefficient against wheel derailment}

To verify the adequacy of the mathematical model of the diesel train car, we will compare the values of the stability margin coefficient against wheel derailment obtained by calculation with the data of experimental studies (Fig. 5).

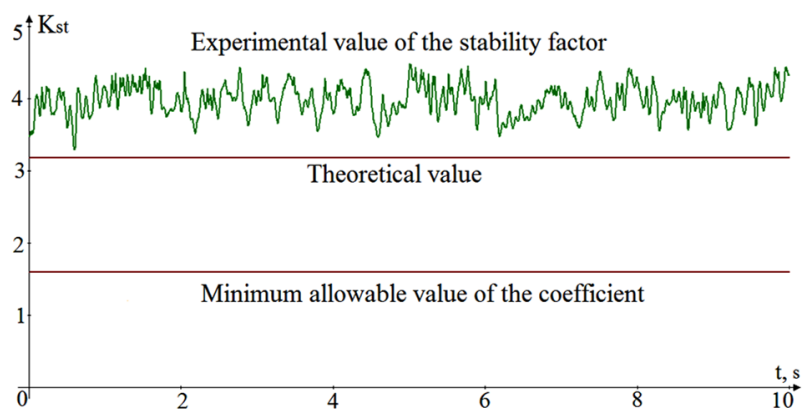

Fig. 5. Comparison of the experimental values of the stability margin coefficient against wheel derailment of the first wheel pair of a diesel train car at the speed of $30 \mathrm{~m} / \mathrm{s}$ on a straight section of the railway with theoretically calculated ones.

Experimental study of the DPKr-2 diesel train was carried out by the "Branch research laboratory of dynamics and rolling stock strength" of Dnipropetrovsk National University of Railway Transport named after Academician V. Lazaryan.

The determination of the dynamic characteristics included in the criteria for the probability of derailment was carried out using strain gauges of the type KF5-P110-200 installed on the axle boxes, as well as sensors of linear displacements WS31-250 with a maximum stroke of $250 \mathrm{~mm}$ and a relative error of $\pm 1 \%$.

All processes using a tensor amplifier of the type TMA-32 with a block of filters and ADC (analog-todigital converter) were transferred to the corresponding software modules.

From Fig. 5 it is evident that the minimum experimental value of the stability margin coefficient against wheel derailment at a speed of the diesel train car of $30 \mathrm{~m} / \mathrm{s}$ is 3,4 . In this case, the minimum theoretical value of the stability margin coefficient against wheel derailment on the first wheel pair at the speed of $30 \mathrm{~m} / \mathrm{s}$ and the average amplitude of horizontal unevenness of $0,006 \mathrm{~m}$ is 3,2 . The difference in the results does not exceed $6 \%$.

\section{Conclusions}

It has been shown that the increase in the speed of the diesel train car leads to deterioration of traffic safety indicators determined by all methods of study. However, the values of the maximum permissible speeds under the same conditions are different. This is conditioned, first of all, by the fact that the coefficient of stability against wheel pair derailment calculated according to car norms [16] does not take into account the influence of rail track unevenness and, therefore, may give a false assessment of the traffic safety parameters.

In assessing the possibility of wheel derailment according to the norms valid on the railways of Ukraine, the values of the frame strength and the coefficient of vertical dynamics are analyzed. At the same time BS EN 14363: 2005 European norms are guided by horizontal guiding force. Therefore, the results obtained by these 
techniques are different. It has been shown that the requirements of European norms are more stringent than those used in Ukraine. So under the same conditions of diesel train movement (straight track section, horizontal unevenness of $20 \mathrm{~m}$ long and amplitude of $10 \mathrm{~mm}$ ) European standards allow for speeds of up to $110 \mathrm{~km} / \mathrm{h}$, norms of a motorized rolling stock [15] allow speeds up to $120 \mathrm{~km} / \mathrm{h}$. and car norms [16] allow for speeds of up to $150 \mathrm{~km} / \mathrm{h}$.

The comparison of the results of the theoretical studies with those from the experimental ones proves the adequacy of the model and the possibility to use it in solving the problems of wheel derailment, since the difference in the results is $6 \%$.

\section{References}

1. Instructions for organization the rebuilding work in the aftermath of transport accidents on the railways of Ukraine. Order of the Ministry of Transport of Ukraine from April 27, 2001 № 258

2. Passenger diesel train DTKr-2. Operating manual DTKr-2.000.000 RE. Part 1, 563 (2014)

3. M. Nadal, Locomotives a Vapeur, Collection encyclopedie scientifique, biblioteque de mecanique appliquee et genie, 186 (1908).

4. A. Chudzikiewicz (eds.), Monitorowanie stanu układu dynamicznego pojazd szynowy - tor, Oficyna Wydawnicza PW, 233 (2012)

5. J. Droździel, E. Kardas-Cinal, B. Sowiński, Railway vehicle safety assessment affected by wheel and rail wear, VSDIA 2010 - 12th International Conference on Vehicle System Dynamics, Identification and Anomalies, Budapest, 8-10 Nov., 81-88 (2010)

6. J. Evans, M. Berg, Challenges in simulation of rail vehicle dynamics, Vehicle System Dynamics: International Journal of Vehicle Mechanics and Mobility, 47, 1023-1048 (2009)

7. C. Hung, Y. Suda, M. Aki, T. Tsuji, M. Morikawa, T. Yamashita, T. Kawanabe, T. Kunimi, Study on detection of the early signs of derailment for railway vehicles, Vehicle System Dynamics, 48, 451-466 (2010)

8. M. Opala, Analysis of experimental data in the context of safety against derailment of a railway vehicle, Key Engineering Materials, 518, 16-23 (2012)

9. A. Shabana, Nadal's formula and high speed rail derailments, J. Comput. Nonlinear Dynam., 7 (2012)

10. J. Xiang, Q. Zeng, Mechanism and energy random analysis of train derailment on railway bridges, International Journal of Structural Stability and Dynamics, 9, 585-605 (2009)

11. J. Elkins, H. Wu, New criteria for flange climb derailment, Railroad Conference, 1-7 (2000)

12. H. Wu, X. Shu, N. Wilson, Flange climb derailment criteria and wheel/rail profile management and maintenance guidelines for transit operations, TCRP Report, 5, 71 (2005)
13. M. Verigo, Interaction of the track and rolling stock, 559 (Moscow, Transport, 1986)

14. M. Verigo, Questions of the interaction of the railway track and rolling stock and the problems of calculating the path, Proceedings of the Central Research Institute of the Ministry of Railways, 268, 125 (1963)

15. Norms for calculating and evaluating the strength of load-bearing elements and the dynamic qualities of a motorized rolling stock. etc. The Ministry of Railways of the Russian Federation is $1520 \mathrm{~mm}$ gauge, VNIIZhT, 147 (1997)

16. Norms for the calculation and design of railroad cars of the Ministry of Railways of gauge $1520 \mathrm{~mm}$ (nonself-propelled), GosNIV-VNIIZhT, 319 (1996)

17. I. Klimenko, Development of theoretical foundations and methods for assessing and improving the safety of rolling stock railroad traffic [Manuscript]: dis. ... dr. techn. sciences, DNUZT, 284 (2015)

18. A. Azovsky, V. Koturanov, M. Ovechnikov, I. Plotnikov, On the estimation of safety from the wheels derailment, Collection of articles of the international conference "Traffic safety of trains", MIIT, (2007)

19. E. Kardas-Cinal, Selected problems in railway vehicle dynamics related to running safety, The archives of transport, 31, 37-45 (2014)

20. E. Sokol, Derailment and collisions of rolling stock (Forensic Examination. Elements of the theory and practice), Transport of Ukraine, 386 (2004)

21. E. Sokol, Train crash (Forensic Expertise, Elements of Theory and Practice), 355 (Phoenix, 2007)

22. A. Kuzyshyn, A. Batig, Construction of the mechanical model of the diesel train DTKr-2 and its features, Bulletin of the DNUZT, 6 (72), 20-30 (2017)

23. S. Kostritsa, Yu. Sobolevskaya, A. Kuzyshyn, A. Batig, Mathematical model of diesel train wagon DPKr-2, Bulletin of the DNUZT, 1 (73), 56-65 (2018) 